\title{
СОВРЕМЕННЫЕ ИНСТРУМЕНТЫ УПРАВЛЕНИЯ МАЛЫМ ПРЕДПРИЯТИЕМ
}

\author{
Тумаков Ильяс Камилович \\ Юсупова Лилия Рафиковна \\ студенты \\ ФГАОУ ВО «Казанский (Приволжский) \\ федеральный университет»
}

\begin{abstract}
Аннотация: в статье описаны современные инструменты управления малым предприятием, функции контроллинга. Также описаны программные обеспечения по управлению малым предприятием, которые включают в себя множество контролируемых процессов, и их ключевые особенности. Приведены причины для перехода к цифровому менеджменту.

Ключевые слова: малые предприятия, бизнес, контроллинг, цифровой менеджмент, программное обеспечение
\end{abstract}

\section{MODERN SMALL BUSINESS MANAGEMENT TOOLS}

\section{Tumakov Ilyas Kamilovich Yusupova Liliia Rafikovna}

\begin{abstract}
: the article describes modern tools for managing a small enterprise, controlling functions. It also describes software for managing a small enterprise, which includes many controlled processes, and their key features. The reasons for the transition to digital management are given.

Key words: small enterprises, business, controlling, digital management, software

В современном мире главным преимуществом любого предприятия становится не владение достаточным количеством факторов производства, а своевременное получение достоверной и актуальной информации. Информация в современном мире - это основной ресурс, на основании которого предприятие должно грамотно, рационально и своевременно принимать управленческие решения. Именно поэтому организации, в особенности малого
\end{abstract}


бизнеса, должны внедрять в свою деятельность самые передовые и инновационные методы управления и контроля. Одним из таких методов считается контроллинг.

На сегодняшний день нет однозначного определения этого понятия. Однако многие исследователи сходятся во мнениях, что контроллинг - это система управления, направленная на определение будущего состояния предприятия и достижение эффективности его деятельности.

Выделяют следующие функции контроллинга:

- сбор и обработка информации для принятия управленческих решений;

- разработка методов ведения контроля по реализации планов предприятия;

- обеспечение рациональности управленческого процесса;

- исследование тенденций развития предприятия в условиях рынка;

- анализ информации о деятельности предприятия.

Контроллинг на сегодняшний день является эффективным инструментом управления предприятиями, который активно применяют в западных странах. С его помощью возможно исследование рынка, что позволяет оценить сложившуюся ситуацию и вовремя среагировать на предстоящие изменения. Особое значение система контроллинга играет для малого бизнеса, поскольку она позволяет ему повысить свою конкурентоспособность за счет увеличения скорости и эффективности принятия управленческих решений.

Современные инструменты управления малым предприятием включают в себя большое количество современных технологий, рассмотрим их более подробно:

1. Инструменты управления взаимоотношениями с клиентами. CRM-программы могут отслеживать почти каждую деталь бизнеса, которая происходит между компанией и ее клиентами, от их платежного адреса до предпочтительного дня доставки. CRM-системы сначала разрабатывались для крупного бизнеса с большими отделами продаж, но теперь эти системы доступны и для малого предпринимательства.

2. Инструменты облачного сотрудничества. За последнее десятилетие предприятия осознали, что хранить информацию, необходимую для ведения бизнеса, в Интернете проще и дешевле, чем на собственных компьютерах. Такое использование Интернета стало известно как «облачные вычисления» или просто «облако». Если используется Gmail для электронной почты или хранение файлов производится на Google Диске, то данные 
компании уже находятся в облаке. Quickbooks предлагает программное обеспечение для бухгалтерского учета, которое не нужно устанавливать на свой компьютер, у него есть версия в облаке. Более новые бухгалтерские программы, такие как Freshbooks и Xero, предназначены только для облачных вычислений.

3. Инструменты электронного выставления счетов. Говоря о современных финансовых услугах, всем малым предприятиям пора оставить бумажные счета-фактуры учебникам истории. Электронные инструменты для выставления счетов можно использовать с компьютера, планшета или смартфона, и многие из них основаны на облачных технологиях. Это позволяет сотрудникам в любое время отправить счет с рабочей площадки: больше не нужно ждать прибытия бухгалтера. Инструменты электронного выставления счетов предлагают разные варианты для малого бизнеса и позволяют клиентам отправлять платежи непосредственно в банк или в электронную платежную систему.

4. Инструменты управления социальными сетями. Сегодня социальные сети являются одной из площадок продвижения продукции компании, поиска новых клиентов, повышения узнаваемости и мониторинга спроса. Существует множество бесплатных или недорогих инструментов управления социальными сетями, например Hootsuite и Buffer. Многие из лучших инструментов управления социальными сетями бесплатны на уровне использования и наиболее распространенными в малом бизнесе.

Также существуют программные обеспечения по управлению малым предприятием, включающим в себя множество контролируемых процессов, а именно:

1. Маркетинг. Программное обеспечение для маркетинга может приумножить результаты обычного маркетолога с помощью мощных инструментов, которые обеспечивают глубокое понимание данных о клиентах, что в конечном итоге приводит к увеличению потенциальных и постоянных покупателей.

2. Бухгалтерский учет. Если необходимо отслеживать транзакции и движение входящих и исходящих денег, современное бухгалтерское программное обеспечение и инструменты помогут в этом малому предприятию. С помощью таких программ появляется возможность не держать в штате бухгалтера, владелец бизнеса сможет сам формировать всю необходимую отчетность. 
3. Управление проектом. Основная цель инструментов управления проектами - следить за командной работой и добиваться оптимального уровня производительности. Программное обеспечение и инструменты для управления проектами предоставляют малым предприятиям услуги по обеспечению сбалансированной рабочей нагрузки для команд и позволяют выполнять поставленные задачи в назначенное время.

В современную эпоху концепция виртуальных рабочих мест и удаленной работы развивается. Программы для малого бизнеса гарантируют, что вся организация компании будет синхронизирована, а деятельность фирмы в целом эффективно оптимизирована.

В таблице 1 представлены самые популярные программные обеспечения по управлению малым бизнесом.

Таблица 1

Популярные программные обеспечения по управлению малым бизнесом

\begin{tabular}{|c|l|}
\hline Название & \multicolumn{1}{|c|}{ Ключевые особенности } \\
\hline «нТаск» & $\begin{array}{l}\text { Низкая цена, отличный функционал } \\
\text { Управление рабочим пространством для команд } \\
\text { Больше возможностей в бесплатной версии } \\
\text { по сравнению с конкурентами }\end{array}$ \\
\hline «Асана» & $\begin{array}{l}\text { Интерактивный интерфейс } \\
\text { Легко использовать } \\
\text { Популярность в деловом мире }\end{array}$ \\
\hline «Трелло» & $\begin{array}{l}\text { Привлекательный интерфейс } \\
\text { Архив записей } \\
\text { Рабочий процесс в стиле канбан }\end{array}$ \\
\hline «Zoоm» & $\begin{array}{l}\text { НD-аудио и видео } \\
\text { Магазин приложений }\end{array}$ \\
\hline «МиксМакс» & $\begin{array}{l}\text { Отслеживание почты и аналитика } \\
\text { Пользовательские шаблоны }\end{array}$ \\
\hline «Лойверс» & $\begin{array}{l}\text { Аналитика продаж } \\
\text { Инвентаризация и управление персоналом }\end{array}$ \\
\hline «Аиtomate.iо» & $\begin{array}{l}\text { Интеграция один к одному } \\
\text { Межфункциональные рабочие процессы }\end{array}$ \\
\hline
\end{tabular}

nTask - инструмент для малого бизнеса, который помогает эффективно управлять задачами и проектами компании. Данная программа больше всего подходит для стартапов и малого бизнеса, так как предлагает учетную запись Forever FREE. По данной причине nTask занимает первое место в рейтинге инструментов для малого бизнеса. 
Асана - это программа, которая является одним из важных инструментов для малого бизнеса. Она используется для сосредоточения на поставленных целях, проектах и оперативных задачах бизнеса, находящихся в стадии роста.

Trello, наряду c nTask и Asana, дополняет тройку программного обеспечения для малого бизнеса. Данная программа позволяет работать совместно с командами, помогает визуально организовывать и расставлять приоритеты командных проектов. Его впечатляющий интерфейс и использование «карточек» пользуются успехом у малых организаций.

Еще одним инструментом для малого бизнеса в настоящее время является приложение для видеоконференций «Zoom». Данная программа предоставляет малым предприятиям возможности и средства для проведения онлайн-встреч и вебинаров с помощью программного обеспечения для видеоконференций, встроенного прямо в основной мессенджер. Бесплатный план Zoom позволяет проводить неограниченное количество встреч, в которых могут участвовать до 100 человек с ограничением в 40 минут.

Следующим в нашем списке инструментов для управления малым бизнесом является MixMax. MixMax — это плагин для браузера, который помогает отслеживать переписку, планировать электронные письма, а также использовать последовательности и напоминания.

Лойверс - это инструмент, предназначенный для оптимизации программ лояльности клиентов путем записи и отслеживания данных о клиентах и предоставления рекомендаций по управлению клиентами. Данный инструмент очень полезен для стартапов на ранней стадии.

Automate.io - это удобное и очень доступное решение для интеграции облачных приложений и сервисов для создания простых рабочих процессов. Данная программа помогает пользователям автоматизировать продажи, маркетинг и различные процессы, связанные с бизнесом, за очень короткое время. Наиболее важной стороной Automate.io является то, что он прост в использовании и не требует каких-либо специальных технических знаний или практики.

Таким образом, рассмотрев современные инструменты управления малым предприятием, можно сделать вывод, что малый бизнес не отстает от крупного в применении инновационных технологий по управлению бизнес-процессами. Для обеспечения конкурентного преимущества, быстрого и стабильного развития деятельности фирмы, необходимо переходить на цифровой 
менеджмент. Для малых предприятий существует множество таких подходов и инструментов, основанных на эффективном управлении фирмой.

\section{Список литературы}

1. Проняева Л.И. Управление развитием малого предпринимательства в регионе / Л.И. Проняева, О.А. Федотенкова // Национальные интересы: приоритеты и безопасность. - 2020. - Т. 16. - № 3(384). - С. 496.

2. Arend R.J. 2014. Social and Environmental Performance at SMEs: Considering Motivations, Capabilities, and Instrumentalism. Journal of Business Ethics 125. - no. 4. - pp. 541.

3. Точинова Ю.С. Методы управления затратами на предприятиях малого бизнеса / Ю.С. Точинова // Актуальные проблемы современной науки: теория и практика: Материалы Международной (заочной) научно-практической конференции, Нефтекамск, 29 мая 2020 года / Под общей редакцией А.И. Вострецова. - Нефтекамск: Научно-издательский центр "Мир науки" (ИП Вострецов Александр Ильич), 2020. - С. 325.

4. Шпортько Ю.В. Использование цифровых технологий управления персоналом в сфере малого бизнеса / Ю.В. Шпортько // VII СПЕРАНСКИЕ чтения. Актуальные проблемы управления в условиях цифровой экономики России: Всероссийская научная конференция: сборник статей, Москва, 01 апреля 2020 года / Российский государственный гуманитарный университет. - Москва: Российский государственный гуманитарный университет, 2020. C. 157.

5. Управление малым бизнесом. Программа MBA 2021 [Электронный pecypc]. - Режим доступа: https://moscow.mba/programs/mini/online/smallbusiness-management?utm_source=yandex.

6. Горбова И.Н. Управление предприятиями малого бизнеса на основе проектного подхода в современных условиях / И.Н. Горбова, В.А. Суровнева, О.А. Базарнова // Экономика и предпринимательство. - 2021. - № 1(126). C. 637. 